\title{
Mensuração de Custos das Perdas Normais e Anormais no Processo Produtivo de uma Indústria Cerâmica
}

Taís Daiane Soares Assumpção Bianchet Mestrado em Ciências Contábeis e Administração pela Universidade Comunitária da Região de Chapecó - UNOCHAPECÓ Professora na UCEFF Faculdades Servidão Anjo da Guarda, n. 295-D, Bairro Efapi - CEP 89809-900 - Chapecó - SC E-mail: taiss@unochapeco.edu.br

Tiago Francisco de Camargo Mestrado em Ciências Contábeis e Administração pela Universidade Comunitária da Região de Chapecó - UNOCHAPECÓ Professor na UCEFF Faculdades Servidão Anjo da Guarda, n. 295-D, Bairro Efapi - CEP 89809-900 - Chapecó - SC E-mail: tiago.camargo@unochapeco.edu.br

Francieli Pacassa Mestrado em Ciências Contábeis e Administração pela Universidade Comunitária da Região de Chapecó - UNOCHAPECÓ Bolsista da Fundação de Amparo à Pesquisa e Inovação de Santa Catarina - FAPESC Servidão Anjo da Guarda, n. 295-D, Bairro Efapi - CEP 89809-900 - Chapecó - SC E-mail: francielipacassa@unochapeco.edu.br

Antonio Zanin Doutorado em Engenharia de Produção pela Universidade Federal do Rio Grande do Sul - UFRGS Professor na Universidade Federal de Mato Grosso do Sul - UFMS Avenida Rosilene Lima Oliveira, 64. Bairro Universitário. Nova Andradina/MS.CEP: 79.750-000 E-mail: zanin.antonio@ufms.br

\section{RESUMO}

O estudo tem como objetivo identificar o custo das perdas do processo fabril de uma indústria cerâmica situada na região oeste de Santa Catarina considerando os princípios de custeio variável, variável parcial, absorção parcial, ideal e total. Metodologicamente a pesquisa classifica-se como descritiva, com abordagem qualiquantitativa e de estudo de caso, realizado em uma indústria de cerâmica vermelha, localizada na região oeste de Santa Catarina. Para a coleta de dados utilizou-se de entrevistas semiestruturadas e análise de documentos da empresa. Posteriormente os dados foram tabulados em planilhas eletrônicas, o que possibilitou a realização dos cálculos de acordo com os princípios de custeio e análise comparativa dos mesmos. Os resultados identificaram os valores das perdas no processo fabril da indústria cerâmica, 
Mensuração de Custos das Perdas Normais e Anormais no Processo Produtivo de uma Indústria

Cerâmica

Taís Daiane Soares Assumpção Bianchet, Tiago Francisco de Camargo, Francieli Pacassa, Antonio

sendo possível avaliar se os padrões de normalidade estabelecidos são condizentes com a situação de análise.

Palavras-chave: Perdas. Indústria Cerâmica. Princípios de custeio.

\section{Measurement of Normal Cost and Abnormal Losses in the Production Process of a Ceramic Industry}

\section{ABSTRACT}

The objective of this study was to identify the value of losses in the manufacturing process of a ceramics industry located in the western region of Santa Catarina considering the principles of variable costing, partial variable, partial and ideal absorption. Methodologically, the research is classified as descriptive, with a qualitative and quantitative approach. The case study was carried out in a red ceramic industry, located in the western region of Santa Catarina. For data collection, semi-structured interviews and analysis of company documents were used. Subsequently, the data were tabulated in electronic spreadsheets, which made it possible to perform the calculations according to the costing principles and a comparative analysis between them. The results identified the value of the losses in the manufacturing process of the ceramic industry, and it is possible to evaluate if the established normality standards are consistent with the analysis situation.

Keywords: Losses. Ceramics industry. Principles of costing.

\section{Medición de Costes de Pérdidas Normales y Anormales em el Proceso Productivo de una Industria Cerámica}

\section{RESUMEN}

El estudio tiene como objetivo identificar el costo de pérdidas en el proceso de fabricación de una industria cerámica ubicada en la región occidental de Santa Catarina considerando los principios de costo variable, variable parcial, absorción parcial, ideal y total. Metodológicamente, la investigación se clasifica como descriptiva, con enfoque cualitativo y cuantitativo y un estudio de caso, realizada en una industria de cerámica roja, ubicada en la región occidental de Santa Catarina. Para la recolección de datos se utilizaron entrevistas semiestructuradas y análisis de documentos de la empresa. Posteriormente, los datos fueron tabulados en hojas de cálculo electrónicas, lo que permitió realizar los cálculos de acuerdo con los principios de costeo y análisis 
Mensuração de Custos das Perdas Normais e Anormais no Processo Produtivo de uma Indústria

Cerâmica

Taís Daiane Soares Assumpção Bianchet, Tiago Francisco de Camargo, Francieli Pacassa, Antonio

comparativo. Los resultados identificaron los valores de pérdidas en el proceso de fabricación de la industria cerámica, lo que permitió evaluar si los estándares de normalidad establecidos son consistentes con la situación de análisis.

Palabras clave: Pérdidas. Industria Cerámica. Principios de cálculo de costos.

\section{INTRODUÇÃO}

A gestão de custos tem se tornado cada vez mais importante no desempenho das organizações, pois para se manterem competitivas e sustentáveis no mercado essas vêm procurando por ferramentas que forneçam informações confiáveis e que apoiem a tomada de decisão com uma maior flexibilidade e eficácia (Quien \& BenArieh, 2008; Wernke et al., 2014).

Assim, seja indústria ou comércio, os gestores buscam obter a maximização dos resultados por meio dos recursos disponíveis, o que acaba por evidenciar a necessidade crescente da gestão de custos, a fim de proporcionar aos usuários internos informações atualizadas com o intuito de estabelecer medidas para minimizar custos e mensurá-los adequadamente conforme as necessidades do processo decisório (Rabelo, Borgert, \& De Medeiros, 2011; Asta \& Barbosa, 2014).

No setor cerâmico brasileiro, tal importância não poderia ser relegada, especialmente por se tratar de um setor em franca expansão nos últimos anos, com um importante parque fabril, tendo produtos de alta qualidade, preços competitivos a nível mundial e abundância de praticamente todas as matérias-primas e recursos técnicos e gerenciais (Bustamante \& Bressiani, 2000). Além de que, conforme Motta, Zanardo e Cabral Juniors (2001), o setor é responsável por um faturamento anual de cerca de US\$ 5 bilhões, equivalente a aproximadamente $1 \%$ do Produto Interno Bruto (PIB).

Diante deste contexto e associado a um processo produtivo geralmente caracterizado por apresentar perdas decorrentes de desperdícios de recursos (como quebras, sobras, retrabalhos, refugos, ociosidades e ineficiências), a demanda na busca pela redução de custos deve ser constante. Para isso, mostra-se de fundamental 
Mensuração de Custos das Perdas Normais e Anormais no Processo Produtivo de uma Indústria

Cerâmica

Taís Daiane Soares Assumpção Bianchet, Tiago Francisco de Camargo, Francieli Pacassa, Antonio

importância a busca do aperfeiçoamento contínuo e eliminação de desperdícios e perdas atreladas à produção, com a finalidade de obter melhor desempenho e evolução no processo de gestão (Asta \& Barbosa, 2014; Serviço Brasileiro de Apoio às Micro e Pequenas Empresas [Sebrae], 2015; Associação Brasileira de Cerâmica [Abceram], 2016).

Logo, com intuito de auxiliar o gestor a realizar um acompanhamento das causas e efeitos atrelada às perdas, mostra-se pertinente conhecer os métodos de custeio que mais se adéquam à mensuração desse tipo de gasto, e que de acordo com Beber et al. (2004) podem ser aplicados levando em consideração os princípios de custeio variável, variável parcial, absorção parcial, ideal e total.

Nesse sentido, como as perdas no âmbito das indústrias cerâmicas podem ser elevadas é pertinente que seja efetuada uma mensuração a respeito, o que requer a escolha de um princípio de custeio apropriado, pois os custos de capacidade ociosa e desperdícios anormais impactam negativamente no custo de produção, e dificulta elevar a competitividade da empresa.

Diante disso, emerge o seguinte problema de pesquisa: como mensurar o custo das perdas normais e anormais do processo produtivo de uma indústria cerâmica com base nos princípios de custeio? Com o propósito de responder essa problemática temse como objetivo do estudo, mensurar o custo das perdas do processo fabril de uma indústria cerâmica situada na região oeste de Santa Catarina.

A relevância da pesquisa está atrelada por tratar-se de um estudo descritivo desenvolvido em uma realidade local, mas extensivo a outros cenários semelhantes, o que permite oferecer conexões importantes entre aspectos teóricos e práticos de mercado. Além disso, os resultados obtidos contribuem com a organização pesquisada ao evidenciar os princípios de custeio que podem ser utilizados em suas atividades. Consequentemente, proporciona melhorias na gestão organizacional e colabora na integração de pesquisa e aplicação prática contábil.

Por fim, a importância também decorre em função da competitividade do setor, instigando as empresas a buscarem excelência no seu processo de produção e 
Mensuração de Custos das Perdas Normais e Anormais no Processo Produtivo de uma Indústria

Cerâmica

Taís Daiane Soares Assumpção Bianchet, Tiago Francisco de Camargo, Francieli Pacassa, Antonio

priorizar qualidade e menor custo. Isso pois, custos anormais inseridos no preço de venda dos produtos, poderá incorrer em perdas de vendas, ou se acompanhar o preço do concorrente ocasiona na possibilidade em trabalhar com baixa margem de lucro e comprometer a saúde financeira da empresa.

Assim sendo, o aperfeiçoamento dos processos e gestão no sistema produtivo, mostra-se importante, bem como a necessidade em compartilhar os desafios com as universidades e buscar estreitar essa relação, tendo em vista que o setor cerâmico é constituído principalmente de pequenas e médias empresas, que nem sempre dispõe de capital e equipe técnica suficientes (Motta et al., 2001).

\section{REFERENCIAL TEÓRICO}

Nesta seção, apresenta-se o embasamento teórico, que servirá de sustentação para a pesquisa e está subdivido na apresentação dos princípios de custeio e das perdas normais e anormais.

\subsection{Princípios de Custeio}

O campo de estudo na área de custos comporta duas grandes definições: princípios de custeio e a forma de processamento dos dados de custos da área fabril. No caso dos princípios de custeio, esses referem-se ao modo como a informação gerada se adequa às necessidades da empresa e quais informações relevantes devem ser fornecidas. Por sua vez, o processamento de dados diz respeito ao procedimento a ser utilizado para obtenção das informações, o que costuma ser denominado método de custeio (Bornia, 2009).

Nesse rumo, Bornia (2009, p. 34) defende uma distinção entre princípios e métodos de custeio, em que "os princípios de custeio são filosofias básicas a serem seguidas pelos sistemas de custos, de acordo com o objetivo e/ou o período de tempo no qual se realiza a análise". Aduz ainda, que os métodos de custeio devem evoluir para atender os princípios e cita alguns exemplos de métodos: UEP (Unidade de 
Esforço de Produção), ABC (Activity-based Costing), RKW (Reichskuratoriun fur Wirtschaftlichtkeit) e Custo Padrão (Kliemann Neto, 1990, 2007; Bornia, 2009).

Os princípios de custeio podem ser definidos como a forma de designar os custos de produção de um determinado produto ou serviço, sendo que esses custos incluem tanto os custos variáveis, que segundo Martins (2010) variam de forma diretamente proporcional à quantidade produzida e os custos fixos, que não estão diretamente ligados ao acréscimo ou decréscimo da produção (Beber et al., 2004), pois dentro de um determinado volume de produção não sofrem alterações.

Logo, a utilização desses métodos possibilitam determinar o valor dos objetos de custos, redução de custos, aperfeiçoamento de processos e outras inúmeras informações para o processo decisório (Abbas, Gonçalves, \& Leoncine, 2012; Da Silva et al., 2018). Entretanto, para efeito deste artigo foram considerados os princípios de (i) custeio variável, (ii) custeio por absorção total e ideal e (iii) de custeio parcial (variável e absorção), conforme evidenciado na Figura 1 e descrito nas próximas seções.

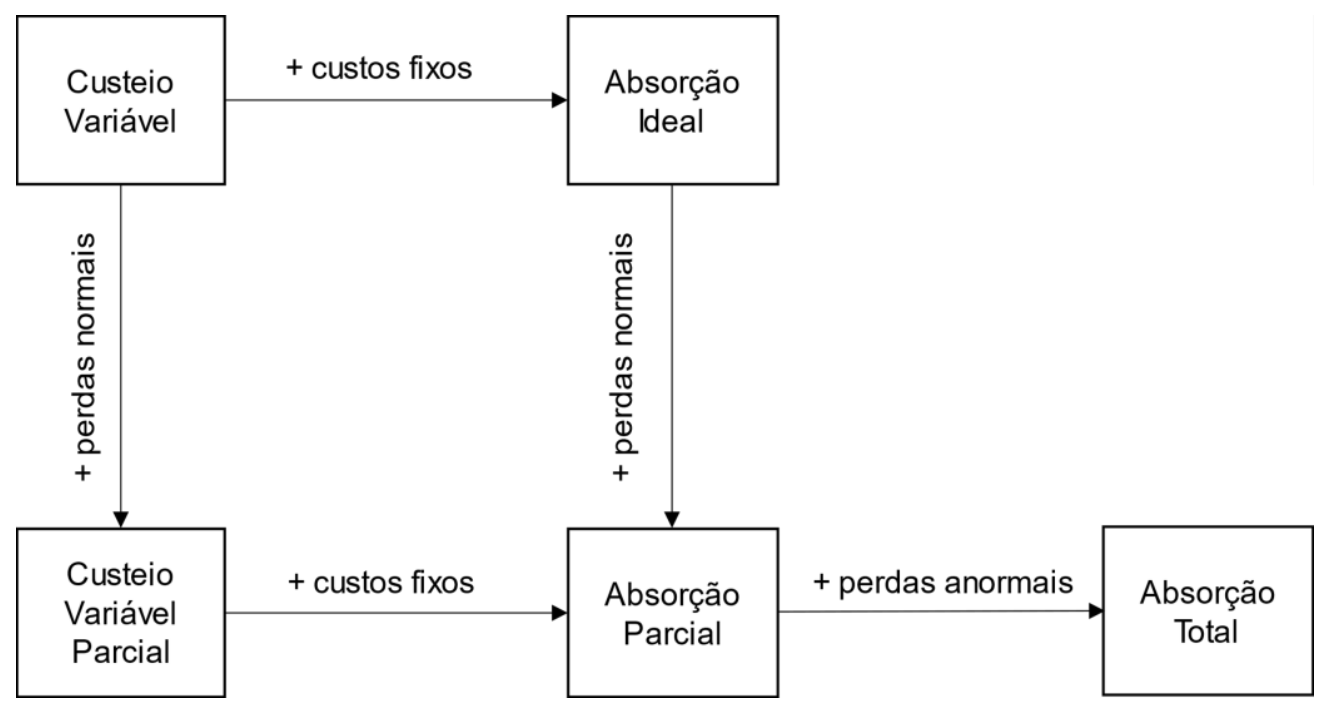

Figura 1. Esquema comparativo entre os princípios Fonte: Beber et al. (2004, p. 5).

Ao vislumbrar a Figura 1, ressalta-se a necessidade da compreensão a despeito 
Mensuração de Custos das Perdas Normais e Anormais no Processo Produtivo de uma Indústria

Cerâmica

Taís Daiane Soares Assumpção Bianchet, Tiago Francisco de Camargo, Francieli Pacassa, Antonio

de cada um desses princípios quanto aos custos e as perdas do processo produtivo. No custeio variável, por exemplo, em relação aos demais não se considera nenhuma perda, o que é uma situação nula de ocorrência, haja vista que toda atividade têm a existência de perdas, mesmo que mínimas (Beber, Silva, Diógenes, \& Kliemann Neto, 2004).

Em contrapartida, os métodos de custeio correspondem a conjuntos de técnicas padronizadas que são utilizadas na determinação de custos totais de produtos e serviços, a fim de possibilitar maiores informações ao processo decisório e de planejamento (Schultz, da Silva, \& Borgert, 2008).

\subsubsection{Princípio de Custeio Variável}

O custeio variável é estruturado para atender a administração da empresa, tendo como premissa básica de que somente os custos variáveis/diretos, ou aqueles que variam de acordo com o volume de produção serão apropriados ao objeto de custeio (Ribeiro, 2009; Megliorini; 2012; Bandeira, Benin, \& Machado, 2017). Portanto, os demais custos necessários para manter a capacidade instalada (indiretos ou fixos) devem ser desconsiderados em termos do custo do produto, sendo contabilizados diretamente no resultado do exercício (Wernke, 2004; Bornia, 2009; Padoveze, 2010).

Nessa perspectiva, Martins (2010) e Abbas et al. (2012) expõem que o custeio variável pressupõe que a análise dos custos fixos na composição do valor de um bem ou serviço vai existir independente do volume produtivo devido a pré-existência de uma estrutura para atender os clientes. Sendo assim, as decisões gerenciais devem ser pautadas nos custos variáveis os quais interferem no custo global dos bens ou serviços.

Ademais, por meio do custeio variável é possível obter a margem de contribuição de um item, o que possibilita avaliar o quanto cada bem ou serviço contribui para cobrir os custos e despesas fixas e gerar lucro (Abbas et al., 2012; Da Silva, Cruz, Dos Santos, \& Leone, 2018). Assim como permite incorrer na análise do custo/volume/lucro que auxilia na avaliação dos resultados em relação às metas estabelecidas e o torna 
Mensuração de Custos das Perdas Normais e Anormais no Processo Produtivo de uma Indústria

Cerâmica

Taís Daiane Soares Assumpção Bianchet, Tiago Francisco de Camargo, Francieli Pacassa, Antonio

indicado principalmente para controles gerenciais (Abbas et al., 2012; Da Silva et al., 2018).

Logo, dentre os benefícios da sua utilização pode-se destacar a possibilidade por parte das organizações em obter vantagem competitiva no mercado e respostas mais eficientes nos cenários de atuação, a partir de uma gestão estratégica de custos, proporcionando ao gestor conhecer efetivamente os seus gastos (Da Silva, et al., 2018).

\subsubsection{Princípio de Custeio por Absorção (total e ideal)}

O princípio de custeio por absorção consiste na apropriação de todos os custos à produção do período (Martins, 2010; Viceconti \& Neves, 2013; Rabelo et al., 2011). O custeio por absorção é considerado como básico para a avaliação de estoques pela contabilidade financeira para fins de levantamento do balanço patrimonial e apuração do resultado com finalidade de atender as exigências da contabilidade societária (Nascimento, 2001; Santos, 2009).

Desse modo, esse sistema de custeio contempla como custos produtivos todos os custos incorridos no processo de fabricação do período, sejam eles diretos ou indiretos, e as despesas são lançadas diretamente no resultado do exercício (Abbas et al., 2012).

Assim, no sistema de absorção integral (ou total) todos os custos fixos e variáveis devem ser repassados aos produtos (Aurora, 2013; Oliveira, Silva, Campos, \& Oliveira, 2015), inclusive as perdas normais e anormais, porque esse princípio trabalha com o conceito de gasto da organização, repassando todas as ineficiências do sistema produtivo ao custo (Kraemer, 1995; Müller, 1996). Nesse caso a empresa perde competitividade, pois em um momento de concorrência acirrada não consegue reduzir/eliminar os custos anormais de seus produtos/serviços, caso acompanhe o preço de mercado, o que ocasiona em uma margem de contribuição reduzida e compromete diretamente a saúde financeira e continuidade do negócio (Kraemer, 1995). 
Mensuração de Custos das Perdas Normais e Anormais no Processo Produtivo de uma Indústria

Cerâmica

Taís Daiane Soares Assumpção Bianchet, Tiago Francisco de Camargo, Francieli Pacassa, Antonio

Em contrapartida, o custeio por absorção ideal distingue-se do custeio por absorção total, uma vez que no custeio por absorção ideal todos os custos (fixos e variáveis) também são computados como custos dos produtos. Mas, os custos relacionados com insumos de forma não eficiente (desperdícios) não são atribuídos aos produtos. Por isso, o custeio por absorção ideal adapta-se particularmente ao auxílio do controle de custos e apoio ao processo de melhoria contínua da empresa (Bornia, 2009).

Kraemer (1995) acresce que o custeio por absorção ideal considera que devem ser alocados aos produtos os custos variáveis com base na ficha técnica do produto, não considerando nenhum tipo de perdas (normal e anormal). O mesmo ocorre com os custos fixos, que não deve absorver a capacidade ociosa, devendo ser excluído do custo do produto, sendo considerado diretamente no resultado do período.

Assim, o custo do produto não pode ser penalizado com as perdas ocorridas no período da avaliação. Os gastos incorridos que não são contemplados neste princípio são mensurados em forma de perdas (normais e anormais), sejam elas decorrentes de ociosidades, ineficiências, retrabalhos ou unidades refugadas. Esse custeio considera um cenário de produção perfeito, sem perdas de materiais e utilizando toda a capacidade instalada (Kraemer, 1995).

O custeio por absorção ideal elimina dos custos dos produtos, inclusive, a ociosidade dos custos fixos para que o produto não receba custos resultantes da ineficiência da empresa no processo de utilização inadequada da sua capacidade de produção. Sobre isso Bornia (2009) argumenta que no custeio por absorção ideal os custos fixos também são computados como custos dos produtos; contudo, os custos fixos relacionados com a capacidade da empresa não usada (ociosidade) ou mal usada (ineficiência), nas suas diferentes formas, são lançados como perdas do período. Dessa forma, as diferentes perdas são isoladas e não creditadas aos produtos.

Esses métodos de custos apresentam vantagens e desvantagens associadas à sua aplicação e apuração dos custos totais dos produtos. Dentre as vantagens, pode-se destacar o fato de que no longo prazo todos os custos devem ser recuperados e 
Mensuração de Custos das Perdas Normais e Anormais no Processo Produtivo de uma Indústria

Cerâmica

Taís Daiane Soares Assumpção Bianchet, Tiago Francisco de Camargo, Francieli Pacassa, Antonio

cobertos pelo preço de venda. E como desvantagens tem o fato da limitação na apresentação dos dados, assim como a arbitrariedade do rateio do custo fixo devido os critérios utilizados (Carneiro, Silva, \& Rocha, 2012; Da Silva, et al., 2018).

\subsubsection{Princípio de custeio parcial (variável e absorção)}

Além dos princípios de custeio já citados, Beber et al. (2004) defendem uma abordagem sobre esses princípios de custeio com a intenção de incorporar dois novos conceitos: Custeio Variável Parcial e Custeio por Absorção Parcial.

No caso do Custeio Variável Parcial, Beber et al. (2004) destacam que esse é derivado do custeio variável, onde ocorre a incorporação dos custos das perdas normais provenientes de quebras, sobras, refugos e retrabalhos, desde que considerados pertinentes ao processo produtivo normal.

Quanto ao Custeio por Absorção Parcial aduzem que esse é derivado do custeio por absorção ideal, mas diferenciando-se desse pelo fato de englobar as perdas normais, sejam elas de refugos, ociosidades, quebras e sobras. Com isso, no custeio por absorção parcial se deve considerar que o custo do produto é independente do volume produzido, de vez que tem acoplado à sua produção uma parcela de perda normal previamente estabelecida (Beber et al., 2004). Dessa maneira, todos os outros gastos podem ser explicados pelas perdas anormais.

Martins e Rocha (2010) argumentam que o Custeio por Absorção Parcial garante que os produtos recebam, na forma de custos, apenas os esforços destinados a produzi-los, reservando os sacrifícios referentes a administrar e vender (despesas) à empresa como um todo, sendo incorporados ao resultado.

Como visto, cada princípio de custeio segue um caminho e pode levar a resultados díspares devido o tratamento das perdas, cabendo ao gestor selecionar aquele que melhor se coaduna com a realidade empresarial ou necessidades gerenciais. Os princípios de custeio "variável", "variável parcial", "absorção parcial", "ideal" e "total" podem ter papel fundamental dentro das organizações, tanto no controle 
Mensuração de Custos das Perdas Normais e Anormais no Processo Produtivo de uma Indústria

Cerâmica

Taís Daiane Soares Assumpção Bianchet, Tiago Francisco de Camargo, Francieli Pacassa, Antonio

dos gastos como para o processo gerencial, auxiliando na tomada de decisões frente às mudanças de mercado que ocorrem no ambiente da empresa.

\subsection{Perdas Normais e Anormais}

Perdas no sentido mais amplo, são bens ou serviços consumidos de forma anormal ou involuntária (Martins, 2010). Não se confundem com a despesa (muito menos com o custo), exatamente por sua característica de anormalidade ou involuntariedade. Não é um sacrifício feito com intenção de obtenção de receita. Esse conceito está relacionado com as perdas anormais, sendo exemplos mais comuns: perdas com incêndios, o obsoletismo de estoques etc (Martins, 2010).

O referido autor também ressalta que inúmeras perdas de pequeníssimo valor são, na prática, comumente consideradas dentro dos custos ou das despesas, sem sua separação, visto que isso é aceitável devido à irrelevância do valor envolvido. Contudo, no caso de montantes apreciáveis, esse tratamento não é correto (Martins, 2010).

No que tange às perdas "normais", essas são inerentes ao próprio processo de produção; são previsíveis e já fazem parte da expectativa da empresa, constituindo-se em um sacrifício necessário para obter o produto. Quanto às perdas "anormais", essas ocorrem de forma involuntária e não representam sacrifício premeditado, como é o caso de danificações extraordinárias de materiais por obsoletismo, degeneração, incêndios, desabamentos e etc (Martins, 2010).

A perda "normal" integra o custo dos produtos, sendo admitida pela própria especificação do processo, a qual dentro do contexto técnico-econômico atual não pode ser recuperada. No caso das perdas “anormais", essas não são incluídas nos custos da produção e são alocadas diretamente para o resultado. Como não estão previstas na especificação do processo, o correto seria estabelecer um plano de ação visando à respectiva eliminação (Beber et al., 2004). Diante disso, tal diferenciação de perdas normais e anormais se faz necessária à medida que o grau de dificuldade no combate e eliminação das perdas inerentes aos processos de produção é maior do que o das perdas anormais (Zanin, Tavares, Wernke, \& Afonso, 2019). 
Mensuração de Custos das Perdas Normais e Anormais no Processo Produtivo de uma Indústria

Cerâmica

Taís Daiane Soares Assumpção Bianchet, Tiago Francisco de Camargo, Francieli Pacassa, Antonio

No que se refere às suas categorias, as perdas "normais" ou "anormais" podem ser segregadas em seis modalidades conforme aponta Silva (2002) e Kliemann Neto (2007):

- Quebras: são as perdas de matérias-primas não passíveis de recuperação como, por exemplo, a perda de peso da borracha natural devido à evaporação da umidade ao longo do processo de fabricação de pneus;

- Sobras: são as perdas de materiais que não foram utilizados na composição do produto (como os cavacos de aço resultantes de um processo de usinagem);

- Retrabalhos: perdas advindas do reprocessamento de materiais semiacabados ou produtos fora das especificações (como os retoques na pintura de peças da lataria ou do carro pronto na indústria automobilística);

- Refugos: são materiais semiacabados ou produtos fora das especificações requeridas pelo processo (ou pelos clientes) para os quais não há possibilidade de retrabalho (ou não seja vantajoso retrabalhá-los);

- Ociosidades: são as disponibilidades de tempo dos recursos (mão de obra e maquinário) não aproveitadas integralmente para agregar valor aos produtos;

- Ineficiências: perdas oriundas dos desvios ocorridos durante a execução do processo com relação às especificações de projeto. Por exemplo: máquinas operando em velocidade reduzida ou mão de obra em ritmo inferior ao esperado.

Como visto, as perdas podem existir em diversos contextos operacionais e um sistema que permita identificar e quantificar quais são as perdas de uma empresa é de grande utilidade para auxílio ao processo de análise e melhoria na eficiência interna dos processos produtivos (Brum, 2006).

No mesmo sentido, Zanella, Deimling, Kruger e Denig (2014) comentam sobre a importância do acompanhamento, por meio de controles contábeis, da identificação dos 
Mensuração de Custos das Perdas Normais e Anormais no Processo Produtivo de uma Indústria

Cerâmica

Taís Daiane Soares Assumpção Bianchet, Tiago Francisco de Camargo, Francieli Pacassa, Antonio

custos de produção, tanto daqueles diretos ou indiretos, fixos e variáveis, quanto daqueles que representam situações de perdas normais, anormais ou da ociosidade dos processos de produção. Assim, para Brum (2006), um dos objetivos da administração deveria ser que seu sistema auxiliasse na melhoria contínua, evitando ou minimizando perdas, visando aperfeiçoar o atendimento aos seus clientes, ampliando sua faixa de mercado, sua receita e seu lucro.

\section{PROCEDIMENTOS METODOLÓGICOS}

Com a finalidade em responder o objetivo do estudo de mensurar o custo das perdas do processo fabril de uma indústria cerâmica situada na região oeste de Santa Catarina. Esta pesquisa em relação à tipologia caracteriza-se como descritiva, pois permite descrever características, registrar, analisar e interpretar sem a intervenção do pesquisador (Andrade, 2002; Gil, 2010).

No que concerne a forma de abordagem, classifica-se como pesquisa quantitativa. O caráter qualitativo possibilitou a realização do estudo em uma situação natural, com foco para a realidade, o que permite ao investigador revisar e aprimorar seu problema de pesquisa conforme a compreensão dos fenômenos, sendo caracterizado por uma estrutura aberta e flexível, além de ser um trabalho rico em dados descritivos (Lüdke \& André, 2013) e possibilita compreender sobre o funcionamento organizacional (Minayo, 2011). Por sua vez, os aspectos quantitativos permitem descobrir numericamente o comportamento dos custos através dos distintos princípios. Logo, os tratamentos quantitativos e qualitativos tornam-se complementares (Minayo, 2011).

Quanto aos procedimentos, classifica-se como um estudo de caso, em que se tem o estudo profundo e exaustivo de um objeto de pesquisa, de modo a obter conhecimentos a respeito (Gil, 2010), e por possibilitar realizar uma análise das variáveis para determinar os efeitos dessas em uma empresa, sistema ou produto (Perovano, 2014). 
Mensuração de Custos das Perdas Normais e Anormais no Processo Produtivo de uma Indústria

Cerâmica

Taís Daiane Soares Assumpção Bianchet, Tiago Francisco de Camargo, Francieli Pacassa, Antonio

O ambiente de pesquisa refere-se a uma indústria cerâmica de pequeno porte localizada no oeste de Santa Catarina. Quanto à escolha da empresa, essa ocorreu devido à acessibilidade aos dados necessários por parte dos pesquisadores, facultada pelo proprietário do empreendimento, além de constituir-se de uma organização que possui uma estrutura produtiva com apenas dez setores e trabalhava com mix composto somente por cinco produtos. Essa configuração acarretou maior facilidade na coleta de dados e na elaboração dos cálculos necessários, bem como proporcionou melhores condições de redigir um texto detalhado abrangendo todos os setores e produtos.

A obtenção dos dados ocorreu através de coleta documental e utilização de entrevistas semiestruturadas aplicadas diretamente ao proprietário da empresa, gerente e um funcionário ligado ao setor de produção, tendo como finalidade levantar os custos e desenvolver a ficha técnica dos produtos. Esse processo de coleta de dados iniciou em fevereiro de 2017 e perdurou até os meses de março e abril do mesmo ano, com o propósito de acompanhar a produção e levantar as possíveis perdas. As informações foram obtidas diretamente de relatórios e controles realizados na empresa.

De posse dessas informações, utilizou-se de planilhas eletrônicas para a realização dos cálculos com base nos princípios de custeio, de modo que efetuou-se uma análise detalhada sobre o processo de produção com objetivo de apurar os custos de produção e as perdas ocorridas no período, classificando as perdas de processos em normais e anormais e utilizando-se da teoria para embasar os resultados e contribuições.

\section{RESULTADOS E DISCUSSÕES}

Fundada em dezembro de 1957, a Olaria Região Oeste (nome fictício) atua na fabricação de tijolos de barro para a construção civil. O processo de produção é contínuo e produz tijolos de barro cozido de 2, 6, 8 e 9 furos. Desses, os tijolos de 2 e 9 furos possuem somente 1 tamanho; os de 8 furos são divididos em 2 tamanhos e os de 
6 furos em 3 tamanhos. Além disso, é feita a compra para revenda de tijolos de 21 furos e maciços. A produção gira em torno de 300.000 a 350.000 mil peças por mês, com revenda mensal de 250 mil unidades.

A partir de tais informações e com base nos relatos do gestor que sinaliza a produção dos tijolos de 6 furos como a base do faturamento da empresa (cerca de 90\%), optou-se por tal produto para a realização dos cálculos dos valores pelos princípios de custeio destacados anteriormente. De modo que, devido às distintas dimensões do produto tijolo de 6 furos, classificou-se na pesquisa como produto $A$ (tijolos de 6 furos com dimensão de $9 \times 14 \times 19 \mathrm{~cm}$ ); produto B (tijolos de 6 furos com

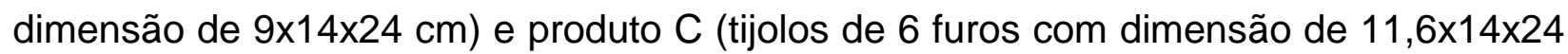
$\mathrm{cm})$.

Quanto ao preço de venda dos produtos, a empresa estipula utilizando um cálculo de custos simples, sem a devida separação dos custos variáveis e fixos, diretos e indiretos, de modo que os custos são alocados igualmente a todos os itens, assim como não tem-se a realização de um controle das perdas produtivas.

No tocando à produção dos itens, esses passam por 7 etapas, começando pela mistura das matérias-primas (barro, serragem e pó de brita). Na sequência, a mistura vai para as formas de moldagem para dar formato ao produto. Posteriormente é realizado o processo de secagem natural, seguida da secagem em estufa, em que 0 produto é direcionado para o cozimento no forno em temperatura aproximada de 780 graus. Por fim, precedente à venda, tem-se a classificação do produto em tipo 1 (ótima qualidade) e tipo 2 (qualidade inferior). O processo produtivo ocorre em três turnos, uma vez que a atividade de cozimento é contínua (24 horas/dia), cabendo aos funcionários realizar revezamento de suas funções. Para tanto, possui 23 funcionários trabalhando nos diversos processos operacionais.

Em relação às perdas produtivas, em sua maioria estão relacionadas às quebras de produtos, uma vez que a produção é influenciada por aspectos climáticos (muito sol e vento ocasiona rachaduras e altos níveis de umidade e tempo chuvoso acarretam em secagem insuficiente). Também pode ocorrer perdas originadas do processo de 
Mensuração de Custos das Perdas Normais e Anormais no Processo Produtivo de uma Indústria

Cerâmica

Taís Daiane Soares Assumpção Bianchet, Tiago Francisco de Camargo, Francieli Pacassa, Antonio

Zanin

queima, pois conforme a situação em que o produto vai para o forno, pode cozinhar além do que é permitido pelos padrões de qualidade.

Tais perdas acarretam na impossibilidade do reaproveitamento da matéria-prima, a qual consequentemente é descartada, diferentemente das perdas que ocorrem antes do produto ir para o forno, que possibilita a reutilização da matéria-prima. Segundo o gestor, algumas perdas normais são admitidas, pois em média ocorre $5 \%$ de refugos e $5 \%$ de quebras, ou seja, um total de $10 \%$.

No tocante aos custos produtivos, cabe mencionar que as matérias-primas consumidas na produção como o barro (argila comum), são obtidas em terras da família do proprietário, sem custo de aquisição. Os demais custos podem ser visualizados na Tabela 1.

Tabela 1

\section{Custos Produtivos}

\begin{tabular}{lccc}
\hline Itens & Quantidade (kg) & Custo Unitário (R\$/kg) & Custo Total (R\$) \\
\hline Serragem & $331.432,50$ & $\mathrm{R} \$ 0,14$ & $46.400,55$ \\
Pó de Brita & $1.878 .117,50$ & $\mathrm{R} \$ 0,04$ & $75,124,70$ \\
Custo Fixo mensal & - & - & $50.000,00$ \\
Despesas do Período & - & - & $2.500,00$ \\
\hline
\end{tabular}

Nota. Fonte: Dados da Pesquisa.

Os dados da Tabela 1, apontam o consumo físico e custo de matéria-prima total entre os meses de fevereiro e março de 2017. O valor do custo fixo mensal da empresa, estimou-se em cerca de $R \$ 50.000,00$ e relaciona-se a itens como mão de obra e energia elétrica. Já outros gastos com o ambiente administrativo, telefone, água e manutenção são as despesas do período e totalizam $R \$ 2.500,00$. Essas são contabilizadas diretamente no resultado, não passando pelo custo dos produtos.

Além das informações descritas, considera-se ainda que a capacidade de produção instalada desta empresa é de 24 horas diárias, mas estima-se que há uma média de $2 \%$ de ociosidade da capacidade total. Já a produção horas/máquina é de 8 horas diárias. 
Mensuração de Custos das Perdas Normais e Anormais no Processo Produtivo de uma Indústria

Cerâmica

Taís Daiane Soares Assumpção Bianchet, Tiago Francisco de Camargo, Francieli Pacassa, Antonio

Para evidenciar o tratamento aplicável às perdas do processo produtivo pelos cinco princípios de custeio em suma, foram levantados os dados a respeito da fabricação dos produtos $A, B$ e $C$ nos meses de fevereiro e março de 2017 , como consta na Tabela 2.

Tabela 2

Dados da produção dos meses de fevereiro e março dos produtos A, B e C

\begin{tabular}{lcc}
\hline Itens & Fevereiro/2017 & Março/2017 \\
\hline Produtos bons (unidade) & 280.025 & 309.975 \\
Refugos (unidade) & 5.601 & 6.199 \\
Tempo de trabalho efetivo $(\mathrm{h})$ & 170 & 187 \\
Matéria-prima consumida $(\mathrm{kg})$ & 1.048 .600 & 1.160 .950 \\
Quebra de matéria-prima $(\mathrm{kg})$ & 14.002 & 15.498 \\
\hline
\end{tabular}

Nota. Fonte: Dados da pesquisa.

Por meio da Tabela 2, pode-se verificar que as quebras de produtos foram estimadas em cerca de $5 \%$ da produção e os refugos aproximam-se de $2 \%$ do volume produzido, tanto em fevereiro quanto em março, demonstrando equilíbrio entre os períodos.

Em seguida, no que diz respeito ao volume de perdas "normais" e "anormais" o levantamento de dados efetuado indicou a realidade exposta na Tabela 3. São considerados como refugos normais, o percentual de tijolos com problemas na queima ou secagem (ficam mais escuros, com deformação e diferença de peso e tamanho), ou seja, são aqueles que algumas vezes ainda podem ser vendidos, mas sem um mercado certo. Já os refugos anormais, é o percentual a mais que pode ocorrer com defeitos e geralmente não é possível o reaproveitamento.

As quebras normais referem-se ao percentual que ocorre com problemas de trinca e deterioração, que deve ser descartado. E as sobras normais são as peças com outros defeitos. Os anormais são tijolos descartados com percentual acima do estabelecido como aceitável. Perdas acima dos percentuais aceitáveis dificilmente se 
Mensuração de Custos das Perdas Normais e Anormais no Processo Produtivo de uma Indústria

Cerâmica

Taís Daiane Soares Assumpção Bianchet, Tiago Francisco de Camargo, Francieli Pacassa, Antonio

Zanin

recuperam no preço de venda, motivo pelo qual deverá se fazer esforço para reduzir ou eliminar.

Tabela 3

Volume de perdas normais e anormais

\begin{tabular}{|c|c|c|c|c|}
\hline \multirow[t]{2}{*}{ Itens (unidade) } & \multicolumn{2}{|c|}{ Fevereiro/2017 } & \multicolumn{2}{|c|}{ Março/2017 } \\
\hline & Volume & Percentual & Volume & Percentua \\
\hline Produção total & 299.628 & $100 \%$ & 331.672 & $100 \%$ \\
\hline Produção boa & 280.025 & $93,46 \%$ & 309.975 & $93,43 \%$ \\
\hline Refugos normais & 5.457 & $1,82 \%$ & 6.087 & $1,84 \%$ \\
\hline Refugos anormais & 144 & $0,05 \%$ & 112 & $0,04 \%$ \\
\hline Quebras normais & 13.720 & $4,58 \%$ & 15.187 & $4,59 \%$ \\
\hline Quebras anormais & 282 & $0,09 \%$ & 311 & $0,10 \%$ \\
\hline Sobras normais & 0 & 0 & 0 & 0 \\
\hline Sobras anormais & 0 & 0 & 0 & 0 \\
\hline $\begin{array}{l}\text { Consumo total prod. boa - } \\
\text { quebras }\end{array}$ & 1.034 .598 & & 1.145 .452 & \\
\hline
\end{tabular}

Nota. Fonte: Dados da pesquisa.

Os dados da Tabela 3 revelam que no total da produção não houve sobras "normais" e nem "anormais". Porém, ocorreram quebras normais de 4,58\% e refugos normais de $1,82 \%$ em fevereiro e de quebras normais de $4,59 \%$ e refugos normais de $1,84 \%$ em março; já as quebras anormais foram de $0,09 \%$ e os refugos anormais de $0,05 \%$ em fevereiro e em março as quebras anormais foram de $0,10 \%$ e refugos anormais foi de $0,04 \%$. Convém destacar, também, que da produção total de 590.000 unidades nos dois meses, 247.812 unidades são referentes à produção do produto $A$, 188.795 unidades são do produto $\mathrm{B}$ e 153.393 unidades do produto $\mathrm{C}$.

No que tange à utilização do tempo de produção, o contexto apurado está representado na Tabela 4. Os gestores da empresa consideram como aceitável uma ociosidade normal de $2 \%$ da capacidade total, considerando a disponibilidade de horas de mão de obra e de máquinas, sendo a diferença, quando houver, considerada como ociosidade anormal. 
Mensuração de Custos das Perdas Normais e Anormais no Processo Produtivo de uma Indústria

Cerâmica

Taís Daiane Soares Assumpção Bianchet, Tiago Francisco de Camargo, Francieli Pacassa, Antonio

Zanin

Tabela 4

Utilização do tempo produtivo (em horas)

\begin{tabular}{lcc}
\hline Itens (horas) & Fevereiro/2017 & Março/2017 \\
\hline Tempo produção boa & 148,8 & 163,68 \\
Tempo refugos & 11,2 & 12,32 \\
Tempo produção total & 160 & 176 \\
Tempo utilizado & 170 & 187 \\
Ociosidade normal & 7 & 7,7 \\
Ociosidade anormal & 3 & 3,3 \\
Ineficiência & 0 & 0 \\
\hline
\end{tabular}

Nota. Fonte: Dados da pesquisa.

No prosseguimento da pesquisa foram coletados os dados referentes aos preços de venda do "milheiro" (lote de 1.000 tijolos) de cada um dos três produtos abrangidos. Nesse sentido, o valor de venda do "milheiro" para o produto A era de $\mathrm{R} \$ 390,00$; para o produto $B$ era de $R \$ 510,00$ e para o produto $C$ o valor era de $R \$ 610,00$. Assim, com os dados necessários coletados, passou-se à mensuração comparativa do custo de produção entre os cinco princípios de custeio selecionados, conforme apresentados na Tabela 5. 
Mensuração de Custos das Perdas Normais e Anormais no Processo Produtivo de uma Indústria

Cerâmica

Taís Daiane Soares Assumpção Bianchet, Tiago Francisco de Camargo, Francieli Pacassa, Antonio

Tabela 5

Custos de produção conforme cada princípio de custeio

\begin{tabular}{|c|c|c|c|}
\hline \multicolumn{2}{|c|}{$\begin{array}{c}\text { Princípios de } \\
\text { Custeio }\end{array}$} & Fevereiro & Março \\
\hline $\begin{array}{l}\text { 1) Custeio } \\
\text { Variável }\end{array}$ & $\begin{array}{l}\text { Variável } \\
\text { Fixo } \\
\text { Total }\end{array}$ & $\begin{array}{c}83.888 \times 0,18=15.099,84 / 280.028 \\
=R \$ 0,054 \\
0 \\
\mathbf{R} \$ \mathbf{0 , 0 5 4}\end{array}$ & $\begin{array}{c}92.876 \times 0,18=16.717,68 / 309.975 \\
=R \$ 0,054 \\
0 \\
\mathbf{R} \mathbf{0}, \mathbf{0 5 4}\end{array}$ \\
\hline $\begin{array}{l}\text { 2) Custeio } \\
\text { Variável } \\
\text { Parcial }\end{array}$ & $\begin{array}{l}\text { Variável } \\
\text { Fixo } \\
\text { Total }\end{array}$ & $\begin{array}{c}15.099,84 \times 1,1080=6.730 .62 / 280.085 \\
=R \$ 0,060 \\
0 \\
\mathbf{R} \mathbf{0 , 0 6 0}\end{array}$ & $\begin{array}{c}16.717,68 \times 1,1080= \\
18.523,19 / 309.975=R \$ 0,060 \\
0 \\
\mathbf{R} \mathbf{0}, \mathbf{0 6 0}\end{array}$ \\
\hline $\begin{array}{l}\text { 3) Custeio } \\
\text { por }\end{array}$ & $\begin{array}{c}\text { Variável } \\
\text { Fixo }\end{array}$ & $\begin{array}{l}R \$ 0,054 \\
R \$ 0,067\end{array}$ & $\begin{array}{l}R \$ 0,054 \\
R \$ 0,054\end{array}$ \\
\hline $\begin{array}{c}\text { Absorção } \\
\text { Ideal }\end{array}$ & Total & $R \$ 0,1210$ & $R \$ \mathbf{0 , 1 0 8 0}$ \\
\hline $\begin{array}{l}\text { 4) Custeio } \\
\text { por }\end{array}$ & $\begin{array}{c}\text { Variável } \\
\text { Fixo }\end{array}$ & $\begin{array}{c}R \$ 0,060 \\
R \$ 0,0038\end{array}$ & $\begin{array}{c}\mathrm{R} \$ 0,060 \\
\mathrm{R} \$ 0,0034\end{array}$ \\
\hline $\begin{array}{c}\text { Absorção } \\
\text { Parcial }\end{array}$ & Total & $R \$ 0,064$ & $R \$ 0,063$ \\
\hline $\begin{array}{l}\text { 5) Custeio } \\
\text { por }\end{array}$ & $\begin{array}{c}\text { Variável } \\
\text { Fixo }\end{array}$ & $\begin{array}{c}R \$ 0,054 \\
R \$ 0,3024\end{array}$ & $\begin{array}{c}R \$ 0,054 \\
R \$ 0,2444\end{array}$ \\
\hline $\begin{array}{c}\text { Absorção } \\
\text { Total }\end{array}$ & Total & $R \$ 0,3564$ & $R \$ 0,2984$ \\
\hline
\end{tabular}

Nota. Fonte: Dados da pesquisa.

A partir da Tabela 5, verifica-se o cálculo dos custos conforme cada princípio de custos abordado. No caso do Custeio Variável foram calculados com base na soma dos custos variáveis (matérias-primas) para produzir cada unidade e deduzido o percentual de $8 \%$ das misturas, onde a quantidade de matéria-prima consumida nos períodos é para a produção total e não somente para uma unidade.

Para tanto, no mês de fevereiro a quantidade de $1.048 .600 \mathrm{~kg}$ de matéria-prima foi utilizada para a produção de 280.025 unidades, enquanto que em março os $1.160 .950 \mathrm{~kg}$ de matéria-prima foram consumidos para a produção de 309.975 unidades. Por esse raciocínio apurou-se que: 
a) Custo variável em fevereiro $=\mathrm{R} \$ 0,18$ (serragem e pó de brita) $\times(1.048 .600$ $\mathrm{kg}-92 \%)=\mathrm{R} \$ 15.099,84 / 280.025$ unidades $=\mathrm{R} \$ 0,054 /$ unidade.

b) Custo em março $=R \$ 0,18 \times(1.160 .950 \mathrm{~kg}-92 \%)=R \$ 16.717,68 / 309.975$ unidades $=\mathrm{R} \$ 0,054 /$ unidade.

No que tange ao Custeio Variável Parcial, por este procedimento o custo foi calculado a partir da matéria-prima utilizada e daquela que é perdida caso ocorram as perdas normais previstas. No contexto pesquisado, então, deve englobar os $5 \%$ de quebras e os $5 \%$ de refugos, como explicitado a seguir:

a) Custo variável em fevereiro $=[(1.048 .600 \mathrm{~kg}-92 \% \times R \$ 0,18) \times 1 /(1-5 \%)] \times$ $[1 /(1-5 \%)]=R \$ 16.730,62 / 280.025$ unidades $=R \$ 0,060 /$ unidade.

b) Custo variável em março $=[(1.160 .950 \mathrm{~kg} \times \mathrm{R} \$ 0,18) \times 1 /(1-5 \%)] \times[1 /(1-5 \%)]$ $=R \$ 18.523,19 / 309.975$ unidades $=R \$ 0,060 /$ unidade.

Nos cálculos citados considerou-se que do valor total dos custos variáveis foram deduzidos os $10 \%$ referentes a refugos e quebras. Quando considerada a concepção do Custeio por Absorção Ideal, a parte "variável" tem a mesma configuração do Custeio Variável conforme comentado anteriormente. Ou seja, o custo variável de $R \$ 0,18$ é multiplicado pela quantidade de quilos de cada período.

Por sua vez, o custo fixo unitário é estabelecido pelo custo referente ao tempo de produção de uma unidade do produto, caso fosse utilizada toda a capacidade de produção de 24 horas por dia. Nesse ponto é pertinente ressalvar que cada produto leva em torno de 15 dias para ficar pronto e que nesses 15 dias no mês de fevereiro ficaram prontas 140.012 unidades e no mês de março 154.987 unidades. Portanto, o cálculo considera: 15 dias $\times 8$ horas $=120$ horas. Com isso, tem-se que:

a) Custo fixo em fevereiro $=(\mathrm{R} \$ 50.000,00 /(24$ horas $\times 28$ dias $) \times(120$ horas $/$ 140.012 horas $)=R \$ 0,067 /$ unidade.

b) Custo fixo em março $=(R \$ 50.000,00 /(24$ horas $\times 31$ dias $) \times(120$ horas $/ 154.987$ horas $)=R \$ 0,054 /$ unidade. 
Mensuração de Custos das Perdas Normais e Anormais no Processo Produtivo de uma Indústria

Cerâmica

Taís Daiane Soares Assumpção Bianchet, Tiago Francisco de Camargo, Francieli Pacassa, Antonio

Nos cálculos citados considerou-se que $\mathrm{R} \$ 50.000,00$ são inerentes aos custos fixos, divididos pelas horas trabalhadas no mês, multiplicado pelas horas que o produto leva para ser concluído.

Quanto ao Custeio por Absorção Parcial, da mesma forma que o custo variável apurado no custeio variável parcial, o custo final engloba as perdas normais. Assim, com base nos dados obtidos tem-se que:

a) Fevereiro: Custo variável $=[(1.048 .600 \mathrm{~kg}-92 \% \times \mathrm{R} \$ 0,18) \times 1 /(1-5 \%)] \times[1 /(1-$ $5 \%)]=R \$ 16.730,62 / 280.025$ unidades $=R \$ 0,060 /$ unidade;

b) Março: Custo variável $=[(1.160 .950 \mathrm{~kg} \times \mathrm{R} \$ 0,18) \times 1 /(1-5 \%)] \times[1 /(1-5 \%)]=\mathrm{R} \$$ $18.523,19 / 309.975$ unidades $=R \$ 0,060 /$ unidade.

Além disso, para os custos fixos devem ser incorporados os custos referentes à ociosidade normal, cuja estimativa do gestor é de que sejam cerca de $2 \%$ da capacidade máxima de horas. Portanto, o cálculo a respeito pode ser assim descrito:

a) Fevereiro: Custo fixo $=[R \$ 50.000,00 /$ (672 horas de capacidade máxima $13,44$ horas ociosas $)] \times 0,0009 \times[1 /(1-5 \%)]=R \$ 0,0038 /$ unidade;

b) Março: Custo fixo $=[R \$ 50.000,00 /$ (744 horas de capacidade máxima $-14,88$ horas ociosas $)] \times 0,0008 \times[1 /(1-5 \%)]=R \$ 0,0034 /$ unidade.

No prosseguimento do estudo foi mensurado o valor com base no princípio do custeio por Absorção Total, que utiliza o conceito de gastos (e não somente dos custos) de cada mês, o que acarreta que se obtenha um valor diferente dos demais princípios. Nesse caso, considera-se que: custo variável = consumo de matéria-prima do período / quantidade de produtos bons do período e que custo fixo $=$ gastos fixos $\mathrm{x}$ tempo de produção de uma unidade / tempo da produção boa.

Nessa direção, a seguir são apresentados os cálculos efetuados no âmbito da indústria pesquisada: 
a) Fevereiro: Custo Variável $=(83.888$ quilos $\times R \$ 0,18 / 280.025$ produtos bons $)=$ $R \$ 0,054$ por unidade. Custo Fixo $=(R \$ 50.000,00 \times 0,0009) / 148,8$ horas de produção boa $=\mathrm{R} \$ 0,3024$ por unidade.

b) Março: Custo Variável $=(92.876$ quilos $\times \mathrm{R} \$ 0,18 / 309.975$ produtos bons $)=\mathrm{R} \$$ 0,054 por unidade. Custo Fixo $=(R \$ 50.000,00 \times 0,0008) / 163,68$ horas de produção boa $=\mathrm{R} \$ 0,2444$ por unidade.

Sendo assim, as principais divergências verificadas nos valores apurados pelos princípios de custeio considerados no estudo estão atreladas às das perdas normais, ou seja, às perdas que são inerentes ao sistema produtivo e dentro de um limite aceitável, devendo ser incorporadas nos preços dos produtos e que antes não estavam sendo consideradas no cálculo dos mesmos. Se o preço de venda praticado não cobrir todos os custos de produção, incluindo as perdas normais e a margem de lucro, não conseguirá se manter no mercado no longo prazo.

Contudo, é relevante identificar que os padrões de normalidade podem mudar ao longo do tempo, pois qualquer mudança na linha de produção pode alterá-los. Então, no processo de decisões deve ser tomado um cuidado maior com os padrões preestabelecidos para que esses estejam coerentes com a realidade fabril da empresa.

Além disso, cabe evidenciar que as perdas tem um percentual significativo no resultado da empresa. Portanto, a partir dos resultados pode-se constatar a importância de conhecer mais adequadamente o que a empresa possui de valores em custos e desperdícios com perdas e ociosidades, possibilitando acompanhar a produção efetuando controles e adoção de medidas de aperfeiçoamento dos processos e atividades.

Ademais, cabe salientar a partir dos resultados obtidos e conforme já evidenciado no estudo de Abbas et al. (2012) e Bandeira et al. (2017), que nenhum dos métodos é perfeito e irá resolver todos os problemas das organizações, todavia, cabe a cada organização realizar a escolha do método mais adequado conforme o tipo de informação desejada. Logo, a adoção de um sistema de custeio deve proporcionar 
Mensuração de Custos das Perdas Normais e Anormais no Processo Produtivo de uma Indústria

Cerâmica

Taís Daiane Soares Assumpção Bianchet, Tiago Francisco de Camargo, Francieli Pacassa, Antonio

benefícios que excedam os custos de implementação, além de mostrar-se suficientes para possibilitar ao gestor analisar as informações geradas e adotar estratégias empresariais adequadas.

\section{CONSIDERAÇÕES FINAIS}

O objetivo do estudo consistiu em mensurar o valor das perdas do processo fabril de uma indústria cerâmica situada na região oeste de Santa Catarina considerando os princípios de custeio. Diante disso, visando atingir tal objetivo foram mensurados os valores das perdas no processo fabril da indústria cerâmica pesquisada considerando os princípios de custeio variável, variável parcial, absorção parcial, ideal e total.

Nesse sentido, apuraram-se os valores díspares de custo unitário conforme cada princípio de custeio conforme salientado a seguir: (i) variável $(R \$ 0,054)$, (ii) variável parcial ( $R \$ 0,060)$, (iii) absorção ideal ( $R \$ 0,1080)$, (iv) absorção parcial $(R \$ 0,063)$, e (v) absorção total $(\mathrm{R} \$ 0,2984)$.

Com base nos valores distintos mensurados, é pertinente considerar que os princípios de custeio apresentados na pesquisa devem ser utilizados de forma conciliada, um em comparação ao outro e um complementando a análise do outro (Zanin et al., 2019). Como visto nos cálculos, a comparação entre eles permitirá que sejam feitas algumas inferências sobre as perdas do processo produtivo, de modo a qualificar a análise por parte do gestor.

Desse modo, concluiu-se que esse enfoque enriquece as informações referentes aos custos incorridos na empresa por meio da utilização conjunta dos cinco princípios de custeio demonstrados, assim, pode-se determinar a quais valores de venda de produtos a empresa sobrevive ao mercado. Adicionalmente, é importante ressaltar que quanto maior o nível de detalhamento das informações, mais embasado estará o gestor no processo de tomada de decisão, pois diante de um ambiente competitivo em que empresas buscam diferentes formas de redução de custos, torna-se indispensável a utilização de uma análise conjunta. 
Mensuração de Custos das Perdas Normais e Anormais no Processo Produtivo de uma Indústria

Cerâmica

Taís Daiane Soares Assumpção Bianchet, Tiago Francisco de Camargo, Francieli Pacassa, Antonio

Ademais, aponta-se a necessidade da organização não adotar apenas um método de custeio, mas uma combinação desses a fim de proporcionar maior número de informações e auxiliar no processo de gestão, além de avaliar estoques, medir os custos dos produtos vendidos e estimar despesas operacionais. Fato, que vai ao encontro dos resultados apresentados por estudos anteriores como Bandeira et al. (2017) e Zanin et al. (2019).

Destaca-se ainda, a importância de se conhecer os custos com base nos princípios de custeios abordados, pois caso o mercado esteja aquecido, possivelmente a empresa conseguirá colocar no mercado os produtos, mesmo que com ineficiências (Absorção Total). Quando da concorrência e retração de mercado, as empresas precisam no mínimo eliminar os custos considerados como anormais (Absorção parcial) sob pena de ter que reduzir a margem de contribuição, tendo problemas no longo prazo. Em caso de o preço de venda não cobrir o Absorção Parcial, a empresa precisa rever seu processo produtivo, no sentido de aumentar a produtividade, reduzindo inclusive perdas consideradas como normais.

Como limitações da pesquisa podem ser mencionados os aspectos ligados à falta de controle e consideração dos gestores do que são consideradas perdas normais ou anormais dentro do período analisado. Outra limitação refere-se ao estudo não ser generalista, pois foi analisada uma única empresa, tornando-se necessário a adoção de um sistema complementando as necessidades de cada empresa.

No que tange às recomendações para trabalhos futuros sugere-se que seja pesquisado a respeito de outras atividades industriais, para analisar o comportamento de diversos ramos, e além de fazer o cálculo do custo somente com os valores desembolsáveis da matéria-prima, também efetuar o cálculo do valor do produto com o custo total, inclusive da matéria-prima própria, sendo que pode haver o custo de oportunidade. 
Mensuração de Custos das Perdas Normais e Anormais no Processo Produtivo de uma Indústria

Cerâmica

Taís Daiane Soares Assumpção Bianchet, Tiago Francisco de Camargo, Francieli Pacassa, Antonio

Zanin

\section{REFERÊNCIAS}

Abbas, K., Gonçalves, M. N., \& Leoncine, M. (2012). Os métodos de custeio: vantagens, desvantagens e sua aplicabilidade nos diversos tipos de organizações apresentadas pela literatura. Contexto, 12(22),145-159.

Associação Brasileira de Cerâmica [Abceram]. Cerâmicas do Brasil - considerações gerais. Mar./2015. Recuperado de: http://www.abceram.org.br/site/index.php?area=2\&submenu=15. Acesso em: jan. 2019.

Andrade, M. M. (2002). Como preparar trabalhos para cursos de pós-graduação: noções práticas (5a ed.). São Paulo: Atlas.

Asta, D. D., \& Barbosa, A. P. (2014). Modelo Conceitual de Mensuração de Desperdícios em Hospitais Privados. Revista de Gestão em Sistemas de Saúde, 3 (1), 40-56.

Aurora, B. (2013). The cost of production under direct costing and absorption costing: a comparative approach. Annals-Economy Series, (2),123-129.

Bandeira, G. G., Benin, M. M., De Souza, M. A., \& Machado, D. G. (2017). Utilização de Métodos de Custeio para fins gerenciais: Aderência Empírica em Empresas da Região Sul do Brasil. SINERGIA-Revista do Instituto de Ciências Econômicas, Administrativas e Contábeis, 21(1), 67-78.

Beber, S. J. N., Silva, E. Z., Diógenes, M. C., \& Kliemann Neto, F. J. (2004). Princípios de custeio: uma nova abordagem. Anais do Encontro Nacional de Engenharia de Produção- ENEGEP. Florianópolis, SC, Brasil, 14.

Bornia, A. C. (2009). Análise gerencial de custos: aplicação em empresas modernas (2a ed.) São Paulo: Atlas.

Brum, D. V. (2006). Identificação no processo produtivo na fabricação de massas alimentícias: um estudo baseado no sistema de custos (Dissertação de Mestrado). Universidade Federal de Santa Maria, UFSM, Santa Maria, RS, Brasil.

Bustamante, G. M., \& Bressiani, J. C. (2000). A indústria cerâmica brasileira. Ceramic News. 7(1), 55-59.

Carneiro Jr, M., Silva, W. V., \& Rocha, D. T. (2012). Custos no Serviço Público: o sistema gerencial de custos do exército. ABCustos, 7(1), 110-131. 
Mensuração de Custos das Perdas Normais e Anormais no Processo Produtivo de uma Indústria

Cerâmica

Taís Daiane Soares Assumpção Bianchet, Tiago Francisco de Camargo, Francieli Pacassa, Antonio

Da Silva, A. C. R., Cruz, V. L., Dos Santos, R. R., \& Leone, R. J. G. (2018). Análise da Gestão Estratégica de Custos e Métodos de Custeio tradicionais em uma Indústria Têxtil Paraibana. ABCustos, 13(1), 58-76.

Gil, A. C. (2010). Métodos e técnicas de pesquisa social (6a. ed.). São Paulo: Atlas.

Kliemann Neto, F. J. (1990). Custos Industriais. Apostila da Disciplina de Custos Industriais, Porto Alegre: PPGEP/UFRGS.

Kliemann Neto, F. J. (2007). Custos Industriais. Apostila da Disciplina de Custos Industriais, Porto Alegre: PPGEP/UFRGS.

Kraemer, T. H. (1995). Discussão de um Sistema de Custeio Adaptado às Exigências da Nova Competição Global. (Dissertação de Mestrado). Universidade Federal do Rio Grande do Sul, UFRGS, Porto Alegre, RS, Brasil.

Lüdke, M., \& André, M. E. D. A. (2013). Pesquisa em Educação: abordagens qualitativas (2a ed.), Rio de Janeiro: E.P.U.

Martins, E. (2010). Contabilidade de custos (10a ed.). São Paulo: Atlas.

Martins, E., \& Rocha, W. (2010). Métodos de custeio comparados: custos e margens analisados sob diferentes perspectivas. São Paulo: Atlas.

Minayo, M. C. S. (2011). Pesquisa social: teoria, método e criatividade. Petrópolis: Vozes.

Motta, J. F. M., Zanardo, A., \& Cabral Júnior, M. (2001). As matérias-primas cerâmicas. Parte I: O perfil das principais indústrias cerâmicas e seus produtos. Cerâmica Industrial, 6 (2), 28-39.

Nascimento, J. M. (2001). Custos: planejamento, controle e gestão na economia globalizada. São Paulo: Atlas.

Megliorini, E. (2012). Custos: análise e gestão. (3a ed.). São Paulo: Pearson Prentice Hall.

Müller, C. J. (1996). A evolução dos sistemas de manufatura e a necessidade de mudança nos sistemas de controle e custeio (Dissertação de Mestrado). Universidade Federal do Rio Grande do Sul, UFRGS, Porto Alegre, RS, Brasil. 
Mensuração de Custos das Perdas Normais e Anormais no Processo Produtivo de uma Indústria

Cerâmica

Taís Daiane Soares Assumpção Bianchet, Tiago Francisco de Camargo, Francieli Pacassa, Antonio

Oliveira, D. F., Silva, R. A. G. Da, Campos, A., \& Oliveira, E. C. (2015). Implementação do sistema de custos no Hospital Universitário Professor Alberto Antunes pela Empresa Brasileira De Serviços Hospitalares - EBSERH. Congresso Brasileiro de Custos. São Leopoldo, RS, Brasil, 22.

Padoveze, C. L. (2010). Contabilidade Gerencial: Um enfoque em Sistema de Informação Contábil. (7a ed.). São Paulo: Atlas.

Perovano, D. G. (2014). Manual de metodologia científica para a segurança pública e defesa social. Curitiba: Juruá, 155-169.

Quien, L., \& Ben-Arieh, D. (2008). Parametric cost estimation based on activity-based costing: a case study for design and development of rotational parts. International Journal of Production Economics, 13(2), 805-818.

Rabelo, E. C., Borgert, A., \& De Medeiros, C. S. C. (2011). Apropriação dos custos indiretos de fabricação em indústrias cerâmicas do sul catarinense. ABCustos, $6(3), 24-45$.

Ribeiro, O. M. (2009). Contabilidade de Custos. São Paulo: Saraiva.

Serviço Brasileiro de Apoio às Micro e Pequenas Empresas [Sebrae]. Construção Civil Cerâmica Vermelha. 2015. Recuperado de: http://www.bibliotecas.sebrae.com.br/chronus/ARQUIVOS_CHRONUS/bds/bds.n sf/b877f9b38e787b32594c8b6e5c39b244/\$File/5846.pdf. Acesso em: ago./2019.

Schultz, C. A., da Silva, M. Z., \& Borgert, A. (2008). É o Custeio por Absorção o único método aceito pela Contabilidade? do Congresso Brasileiro de Custos. Curitiba, PR, Brasil, 15.

Silva, E. Z. (2002). Autonomação e a Eliminação das Perdas: A Base de uma Estratégia de Produção para Assegurar uma Posição Competitiva na Industria. (Dissertação de Mestrado). Universidade Federal do Rio Grande do Sul, UFRGS, Porto Alegre, RS, Brasil.

Viceconti, P., \& Neves, S. (2013). Contabilidade de Custos: um enfoque direto e objetivo. (11a ed.) São Paulo: Saraiva.

Wernke, R. (2004). Gestão de Custos: uma abordagem prática (2a ed.). São Paulo: Atlas. 
Wernke, R., Junges, I., Lembeck, Marluce, \& Medeiros, J. P. (2014). Planilha de custos para empresa de costura industrial terceirizada pelo método TDABC. Congresso Brasileiro de Custos. Natal, RN, Brasil, 21.

Zanella, C., Deimling, M. F., Kruger, S. D., \& Denig, G. C. (2014). A relação das perdas normais e anormais e da ociosidade com os custos de produção de uma empresa calçadista do estado de Santa Catarina. Qualitas Revista Eletrônica, 16(2), 1-15.

Zanin, A., Tavares, G. D., Wernke, R., \& Afonso, P. S. L. P. (2019). Mensuração do valor de perdas no processo produtivo caso de uma indústria de inseticidas. Congreso Internacional De Costos. Mendoza, Argentina, 16.

Data de Submissão: 05/11/2020

Data de Aceite: 09/04/2021 